Disability and Rehabilitation: Assistive Technology

\title{
Assistive technologies, educational engagement and psychosocial outcomes among students with disabilities in higher education
}

\section{Aoife McNicholl, Deirdre Desmond \& Pamela Gallagher}

To cite this article: Aoife McNicholl, Deirdre Desmond \& Pamela Gallagher (2020): Assistive technologies, educational engagement and psychosocial outcomes among students with disabilities in higher education, Disability and Rehabilitation: Assistive Technology, DOI: 10.1080/17483107.2020.1854874

To link to this article: https://doi.org/10.1080/17483107.2020.1854874

Published online: 15 Dec 2020.

Submit your article to this journal $\square$

Џll Article views: 342

à

View related articles $\sqsubset$

View Crossmark data \lceil 


\title{
Assistive technologies, educational engagement and psychosocial outcomes among students with disabilities in higher education
}

\author{
Aoife McNicholl ${ }^{\mathrm{a}}$ (D) Deirdre Desmond ${ }^{\mathrm{b}}$ (D) and Pamela Gallagher ${ }^{\mathrm{a}}$ \\ ${ }^{\mathrm{a} S}$ School of Psychology, Dublin City University, Glasnevin, Ireland; ${ }^{\mathrm{b}}$ Department of Psychology and Assisting Living and Learning Institute, \\ Maynooth University, Maynooth, Ireland
}

\begin{abstract}
Purpose: Increasing numbers of students with disabilities are accessing higher education each year, yet little is known about their assistive technology (AT) needs and its influence on relevant outcomes. The aim of this study was to examine met/unmet AT needs on educational engagement, academic self-efficacy and well-being and the impact of AT use in the areas of competence, adaptability and self-esteem for students with disabilities in higher education in Ireland.

Methods: One hundred and eleven students with disabilities completed a cross-sectional online survey comprising the College Learning Effectiveness Inventory, the Student Course Engagement Questionnaire, the Self-Efficacy for Learning Form Abridged, the Psychosocial Impact of Assistive Devices Scale, and the Warwick-Edinburgh Mental Well-Being Scale.

Results: AT use was found to have a positive psychosocial impact in the areas of competence, adaptability and self-esteem. Those whose AT needs were fully met scored significantly higher on academic selfefficacy, well-being, and on 4 of the 10 educational engagement subscales compared to those who had unmet AT needs. Met/unmet AT needs were not predictive of educational engagement.

Conclusion: These findings highlight the importance of AT from both educational engagement and psychosocial perspectives for students with a wide variety of disability diagnoses. The wide-reaching benefits of AT must be considered by governmental departments when making funding allocations to disability services within higher education institutions.
\end{abstract}

\section{ARTICLE HISTORY}

Received 13 July 2020

Revised 18 November 2020

Accepted 19 November 2020

\section{KEYWORDS}

Assistive technology; educational engagement; academic self-efficacy; wellbeing; quality of life; higher education; disability

> IMPLICATIONS FOR REHABILITATION

- Students with disabilities can face many additional challenges within the higher education environment.

- Findings from this research show that access to appropriate assistive technology can support students' educational engagement, increase well-being and academic self-efficacy and have a positive impact in the areas of competence, adaptability and self-esteem.

- Disability and Assistive Technology Officers in higher education should be cognizant of both the educational and psychological benefits of assistive technology across diverse students with various disability diagnoses.

- Policy makers should consider the wide-reaching benefits of assistive technology when making funding allocations to higher education institutions.

\section{Introduction}

Increasing numbers of students with disabilities (SWD) are accessing and completing higher education across Europe, Canada, Australia and in the US [1-5]. SWD indicate that performing well academically is central to their self-identification as college students [6], yet they are also more likely to struggle with coursework, have lower grades, drop out of, and fail modules in comparison to non-disabled peers [7-9]. Many also report lower academic self-efficacy and greater concerns over their capabilities to achieve the same grades as students without disabilities [10]. Furthermore, SWD in higher education report lower quality of life and more anxiety in comparison to students without disabilities $[11,12]$. In general, higher education can be challenging with many students experiencing instability and uncertainty, and engaging in identity exploration [13]. SWD may face additional identity challenges such as negotiating the increased visibility associated with using accommodations and managing stigma related to disability [14-17].

Assistive technology (AT) can be a vital support for people who experience impairments at any stage across the lifespan [18]. As an enabler, AT is useful in a wide array of contexts and can have a variety of impacts including improving access to education and employment, increasing functional abilities, well-being and sense of autonomy, and enabling civic and social participation [18]. The use/non-use of AT can be influenced by personal (age, gender, mood, diagnosis, disease progression, acceptance of disability), device (quality, ease of use and aesthetics of AT), environmental (social support network, physical barriers) and intervention related factors (users' involvement and preferences in device selection, provision of training, follow up services) $[19,20]$. Those 
who need AT also may struggle to access it due to a lack of affordability, awareness and availability of AT devices, a scarcity of trained AT professionals and insufficient AT-related governmental funding and policies [21].

Findings from our recent systematic review of the impact of AT for SWD in higher education, which included 26 papers, indicated that AT use can support ability to perform academic tasks, engagement with educational materials, and academic performance [22]. Psychological and social benefits of AT use included increased self-confidence and sense of autonomy, changing negative perceptions of others, and better interactions with peers and lecturers, both inside and outside the classroom [22]. We identified gaps and limitations in the research literature including emphasis on performance of specific academic tasks [23,24], without consideration of more holistic educational engagement. Further, no research to date has considered AT use broadly across a diverse sample of students with various disabilities and its relationship with multiple facets of educational engagement.

Gaps also exist in the literature in relation to the psychosocial benefits of AT use in higher education for SWD. The association between AT use and academic self-efficacy has been explored among high school SWD [25]. These findings may not be generalizable to higher education settings given differences in organization and cultures. SWD in higher education may face challenges such as finding suitable, accessible accommodation to enable independent living, the need to self-advocate for supports, and organizing and managing personal assistants [26,27]. Previous research has explored the relationship between AT use and quality of life among higher education SWD [28,29]. However, it may be useful to examine the influence of personal and contextual factors such as age, category of disability and frequency of AT use on quality of life-related outcomes within higher education, given their potential to moderate the relationship [30-33]. Furthermore, previous studies have focussed on AT use rather than met versus unmet needs and its relationships with outcomes in higher education. The present study will address the aforementioned gaps in the literature.

The current study aims to explore the patterns of relationships between AT needs and educational engagement and psychosocial outcomes. The term AT needs is used to distinguish between: (1) those whose AT needs are fully met; and (2) those who have unmet AT needs, including those using AT but also have further requirements and those not currently using AT but reporting need.

The specific objectives of this study were:

1. To explore differences between those who report met and unmet AT needs in educational engagement, academic selfefficacy and well-being.

2. To explore the psychosocial impact of AT use in the areas of competence, adaptability and self-esteem as measured by the Psychosocial Impact of Assistive Devices Scale (PIADS) and the influence of age, gender, category of disability and frequency of AT use.

3. To determine if AT needs (met versus unmet) predicts students' educational engagement when the effects of gender, well-being and academic self-efficacy are controlled for.

\section{Materials and methods}

\section{Participants}

Individuals aged 18 years or over, currently studying in a Higher Education Institution (HEI) in Ireland (https://hea.ie/higher-education-institutions $/ \mathrm{v}=\mathrm{I}$ ), with any form of disability, and using or potentially benefiting from any form of AT, were eligible to participate. Disability was defined as "a state of decreased functioning associated with disease, disorder, injury, or other health conditions, which in the context of one's environment is experienced as an impairment, activity limitation, or participation restriction" [34,p.1220]. Assistive technology was defined as "any product whose primary purpose is to maintain or improve an individual's functioning and independence and thereby promote their wellbeing" [35,p.2229].

\section{Procedure}

Ethical approval was received from the Dublin City University Research Ethics Committee. Multiple platforms were used to disseminate information about the study to potential participants: Disability/AT officers in thirteen HEls circulated the study link and information to students registered with the disability support services at their institutions; and Disability Officers in the Student's Unions of six HEls circulated the study link and information to their members (collectively these approaches covered 15 of the HEls contacted). In addition, the study was promoted through a dedicated Twitter account and Facebook page, and eight disability organizations shared the study details through their social media channels and newsletters. Participation in this study involved completing an anonymous survey through the Qualtrics online platform (https://www.qualtrics.com/uk/). Participants were able to access the survey via computer, phone, or any smart device. The survey took approximately $30 \mathrm{~min}$ to complete.

\section{Measures}

\section{Background information and at profile}

Information on gender, age, category of disability, and year and programme of study were collected. AT users were asked about the types of AT used, frequency of use, satisfaction with AT and unmet AT needs. Non-users were asked about any AT requirements and reason for non-use, if relevant.

\section{Educational engagement}

Educational engagement was defined as engagement in all aspects of college life including academic, social and extra-curricular activities.

The College Learning Effectiveness Inventory (CLEI) [36] examines attitudes, behaviours and dispositions important for academic success in higher education students. It consists of 50 items across six subscales: academic self-efficacy (14 items); organization and attention to study ( 8 items); stress and time press (6 items); involvement with college activity (9 items); emotional satisfaction (7 items); and class communication (6 items). Each item is rated on a 5 -point Likert scale ( $1=$ never and $5=$ always). A raw mean score is produced for each subscale which can range from 1.0 (lowest possible score) to 5.0 (highest possible score). Higher scores on each subscale indicate more positive levels of the attribute. The CLEI has demonstrated adequate reliability and predictive validity [36,37].

The Student Course Engagement Questionnaire (SCEQ) [38] measures academic engagement in a course of study. It consists of 23 items across four subscales: emotional engagement ( 5 items); participation/interaction engagement (6 items); performance engagement ( 3 items); and skills engagement ( 9 items). Each item is rated on a 5 -point Likert scale $(1=$ not at all characteristic of me and $5=$ very characteristic of me). Higher scores on each subscale 
indicate more positive levels of the attribute. Scores for each subscale are calculated by adding up scores for items within the subscale. A total score is calculated by adding up scores for all items. The SCEQ was designed for use among students in higher education and has demonstrated good internal consistency, as well as convergent and discriminant validity through its association with measures of student learning and motivation $[38,39]$.

\section{Psychosocial measures}

The Self-Efficacy for Learning Form - Abridged (SELF-A) [40] assesses academic self-efficacy when carrying out common educational tasks such as note-taking, test preparation and studying. It is a unidimensional measure consisting of 19 items. Students respond to each item by selecting a score from 0 to 100 $(0=$ definitely cannot $d o$ it and $100=$ definitely can do it). The SELF-A is scored by calculating the mean of all the items. Higher scores indicate greater confidence in learning. The SELF-A has demonstrated good reliability and validity [40].

The Warwick-Edinburgh Mental Well-Being Scale (WEMWBS) [41] is a 14-item unidimensional measure which assesses key concepts of mental well-being such as positive affect, satisfaction with interpersonal relationships, and positive functioning. All items are positively worded and each item is rated on a 5-point Likert scale $(1=$ none of the time and $5=$ all of the time). Scores range from 14 to 70. Higher scores indicate better mental well-being. The WEMWBS has demonstrated good face and content validity, and internal consistency (Cronbach's alpha $=0.89$ ) [41].

The Psychosocial Impact of Assistive Devices Scale (PIADS) [42] assesses the impact of assistive device use on functional independence, well-being and quality of life of users. Respondents currently using AT, were asked to consider the assistive device(s) which impact on their educational engagement when completing the PIADS. The PIADS consists of 26 items which comprise three subscales: competence ( 12 items); adaptability ( 6 items); and selfesteem (8 items). Each item is rated on a 7-point scale from -3 (maximum negative impact) to +3 (maximum positive impact). For detailed information on the scoring of each subscale, see [42]. Higher scores on each subscale indicate more positive levels of the attribute. A score of 0 indicates no perceived impact. The PIADS has demonstrated good internal consistency, test-retest reliability, construct and concurrent validity $[42,43]$.

\section{Data analysis}

The IBM statistical software package SPSS (Version 24, SPSS Inc., Chicago, IL) was used to analyze the data. Normality testing was carried out on all variables. Normality was assumed if the histogram was approaching a bell-shaped curve and if skewness values were between \pm 1 . Parametric ( $t$-tests) and non-parametric (Mann-Whitney $U$-tests, Kruskal-Wallis tests) tests were conducted as appropriate to examine differences between AT needs groups (i.e., those reporting met AT needs versus unmet AT needs) in educational engagement and psychosocial measures and the influence of personal factors (i.e., gender, disability category) and AT characteristics (frequency of use) on psychosocial impact as measured by PIADS. Pearson correlations were conducted to examine the relationship between age and psychosocial impact.

In preparation for hierarchical multiple regression (HMR) analyses, gender was binary coded to represent female $(=1) /$ male $(=0)$. "Other" gender was not included for analyses given the small number of cases. "AT needs" was binary coded to represent met AT needs $(=1)$ /unmet AT needs $(=0)$. For HMR analyses, only educational engagement subscales which demonstrated significant univariate relationships with AT needs were retained as outcomes (see Table 4).

In each regression model, gender was entered in block 1, wellbeing (WEMWBS) and academic self-efficacy (SELF-A) in block 2 and AT needs in block 3. This allowed for examination of the unique contribution of AT needs on the outcomes after controlling for gender, well-being and academic self-efficacy. A priori decision was made to exclude the academic self-efficacy subscale of the CLEI as an outcome due to potential multicollinearity with the SELF-A (see Table 1 for intercorrelations between scales). Preliminary analyses confirmed the data did not violate the assumptions of normality, linearity, multicollinearity, homoscedasticity and independence of residuals for any of the models; no multivariate outliers were present. The significance level $(\alpha)$ was set at 0.05 .

\section{Results}

\section{Sample characteristics}

One hundred and eleven participants completed the survey (see Table 2; 32 males; 77 females; 2 identifying as other). Participants ranged in age from 18 to 67 years (median age $=22$ years, mean age $=28.59$ years, $S D=12.75$ ). Thirty-nine participants reported having multiple disabilities; the disabilities of 21 respondents were categorized as "other" (which included Aspergers/Autism, ADD/ADHD, Developmental Coordination Disorder - Dyspraxia/ Dysgraphia, a significant ongoing illness and a speech and language disability); 21 respondents reported a specific learning difficulty.

Table 1. Pearson correlations between all educational engagement, well-being and academic self-efficacy outcome measures

\begin{tabular}{|c|c|c|c|c|c|c|c|c|c|c|c|c|c|}
\hline Variables & 1 & 2 & 3 & 4 & 5 & 6 & 7 & 8 & 9 & 10 & 11 & 12 & 13 \\
\hline 1. ASE subscale & 1 & $0.532 * *$ & $0.479 * *$ & $0.319 * *$ & $0.581 * *$ & $0.486^{* *}$ & $0.674 * *$ & $0.592 * *$ & $0.544 * *$ & $0.386 * *$ & $0.654 * *$ & $0.619 * *$ & $0.419 * *$ \\
\hline 2. OAS subscale & $0.532 * *$ & 1 & $0.541 * *$ & 0.117 & $0.413^{* *}$ & $0.330 * *$ & $0.697 * *$ & $0.769 * *$ & $0.536 * *$ & $0.316^{* *}$ & $0.459 * *$ & $0.565^{* *}$ & $0.337^{* *}$ \\
\hline 3. STP subscale & $0.479 * *$ & $0.541^{* *}$ & 1 & $0.231 *$ & $0.515^{* *}$ & $0.473^{* *}$ & $0.443^{* *}$ & $0.424^{* *}$ & $0.293^{* *}$ & $0.251^{* *}$ & $0.447^{* *}$ & $0.605^{* *}$ & $0.513^{* *}$ \\
\hline 4. ICA subscale & $0.319 * *$ & 0.117 & $0.231^{*}$ & 1 & $0.470 * *$ & 0.176 & $0.283 * *$ & 0.160 & $0.197^{*}$ & $0.382 * *$ & 0.162 & $0.360^{* *}$ & $0.421 * *$ \\
\hline 5. ES subscale & $0.581 * *$ & $0.413^{* *}$ & $0.515^{* *}$ & $0.470 * *$ & 1 & $0.472 * *$ & $0.580 * *$ & $0.385^{* *}$ & $0.543 * *$ & $0.517^{* *}$ & $0.443 * *$ & $0.629 * *$ & $0.517^{* *}$ \\
\hline 6. CC subscale & $0.486^{* *}$ & $0.330 * *$ & $0.473 * *$ & 0.176 & $0.472^{* *}$ & 1 & $0.541 * *$ & $0.278 * *$ & $0.418 * *$ & $0.595^{* *}$ & $0.562^{* *}$ & $0.543^{* *}$ & $0.463^{* *}$ \\
\hline 7. SCEQ total & $0.674^{* *}$ & $0.697^{* *}$ & $0.443^{* *}$ & $0.283^{* *}$ & $0.580^{* *}$ & $0.541 * *$ & 1 & $0.864^{* *}$ & $0.831^{* *}$ & $0.728^{* *}$ & $0.697 * *$ & $0.686^{* *}$ & $0.497 * *$ \\
\hline 8. SE subscale & $0.592 * *$ & $0.769 * *$ & $0.424 * *$ & 0.160 & $0.385^{* *}$ & $0.278 * *$ & $0.864 * *$ & 1 & $0.608 * *$ & $0.389 * *$ & $0.538 * *$ & $0.592^{* *}$ & $0.341 * *$ \\
\hline 9. EE subscale & $0.544^{* *}$ & $0.536^{* *}$ & $0.293 * *$ & $0.197 *$ & $0.543^{* *}$ & $0.418^{* *}$ & $0.831 * *$ & $0.608 * *$ & 1 & $0.541 * *$ & $0.495 * *$ & $0.560 * *$ & $0.381 * *$ \\
\hline 10. PIE subscale & $0.386^{* *}$ & $0.316^{* *}$ & $0.251^{* *}$ & $0.382 * *$ & $0.517^{* *}$ & $0.595^{* *}$ & $0.728 * *$ & $0.389^{* *}$ & $0.541 * *$ & 1 & $0.389 * *$ & $0.468 * *$ & $0.460 * *$ \\
\hline 11. PE subscale & $0.654^{* *}$ & $0.459 * *$ & $0.447 * *$ & 0.162 & $0.443^{* *}$ & $0.562 * *$ & $0.697 * *$ & $0.538 * *$ & $0.495 * *$ & $0.389 * *$ & 1 & $0.548^{* *}$ & $0.459 * *$ \\
\hline 12. SELF-A & $0.619 * *$ & $0.565^{* *}$ & $0.605 * *$ & $0.360 * *$ & $0.629 * *$ & $0.543^{* *}$ & $0.686 * *$ & $0.592 * *$ & $0.560 * *$ & $0.468 * *$ & $0.548 * *$ & 1 & $0.593 * *$ \\
\hline 13. WEMWBS total & $0.419 * *$ & $0.337 * *$ & $0.513 * *$ & $0.421 * *$ & $0.517 * *$ & $0.463^{* *}$ & $0.497 * *$ & $0.341 * *$ & $0.381 * *$ & $0.460 * *$ & $0.459 * *$ & $0.593 * *$ & 1 \\
\hline
\end{tabular}

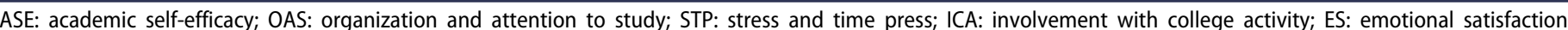

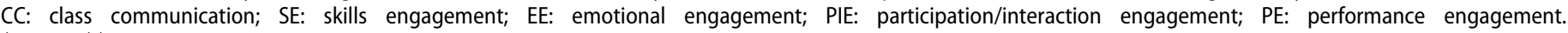
$*_{p}<.05 ; * * p<.01$. 
Table 2. Demographic and academic characteristics of participants.

\begin{tabular}{|c|c|c|}
\hline & $N$ & $\%$ \\
\hline Total & 111 & \\
\hline \multicolumn{3}{|l|}{ Gender } \\
\hline Males & 32 & 28.8 \\
\hline Females & 77 & 69.4 \\
\hline Other & 2 & 1.8 \\
\hline \multicolumn{3}{|l|}{ Category of disability } \\
\hline Blindness, deafness, severe hearing or vision impairment & 11 & 9.9 \\
\hline Physical condition & 11 & 9.9 \\
\hline Specific learning difficulty & 21 & 18.9 \\
\hline Psychological / emotional condition & 8 & 7.2 \\
\hline Other disability & 21 & 18.9 \\
\hline Multiple disabilities & 39 & 35.1 \\
\hline \multicolumn{3}{|l|}{ Registration with disability office } \\
\hline Yes & 104 & 93.7 \\
\hline No & 7 & 6.3 \\
\hline \multicolumn{3}{|l|}{ Type of programme } \\
\hline Advanced certificate/higher certificate/ordinary bachelor degree & 23 & 20.7 \\
\hline Honours bachelor degree/higher diploma & 68 & 61.3 \\
\hline Postgraduate taught programme & 16 & 14.4 \\
\hline Research degree & 3 & 2.7 \\
\hline \multicolumn{3}{|l|}{ Year of study } \\
\hline 1 & 42 & 37.8 \\
\hline 2 & 24 & 21.6 \\
\hline 3 & 28 & 25.2 \\
\hline 4 & 14 & 12.6 \\
\hline \multicolumn{3}{|l|}{ Mode of study } \\
\hline Full time & 96 & 86.5 \\
\hline Part time & 15 & 13.5 \\
\hline \multicolumn{3}{|l|}{ Discipline of study } \\
\hline Science, Maths, Computing, Engineering, Manufacturing \& Construction & 28 & 25.2 \\
\hline Social Science, Business and Law & 26 & 23.4 \\
\hline Education and Training, Humanities and Arts & 35 & 31.5 \\
\hline Agriculture and Veterinary, Health and Welfare, Services & 5 & 4.5 \\
\hline Other & 17 & 15.3 \\
\hline
\end{tabular}

Table 3. AT profile of current users.

\begin{tabular}{lll}
\hline & $N$ & $\%$ \\
\hline Total & 82 & \\
Types of AT used & & \\
Educational assistive technology & 50 & 61 \\
Aids to hearing & 4 & 4.9 \\
Visual aids & 1 & 1.2 \\
Mobility aids & 1 & 1.2 \\
Other & 8 & 9.8 \\
Multiple ATs & 18 & 22 \\
Use of AT apps & & \\
Yes & 27 & 32.9 \\
No & 55 & 67.1 \\
Frequency of AT use for educational engagement & & \\
$\quad$ Everyday & 54 & 65.9 \\
Once or twice a week & 15 & 18.3 \\
Every couple of weeks & 7 & 8.5 \\
Once or twice a month & 1 & 1.2 \\
Rarely/not at all & 5 & 6.1 \\
Satisfaction with AT for educational engagement & & \\
Extremely satisfied & 32 & 39 \\
Somewhat satisfied & 44 & 53.7 \\
Neither satisfied nor dissatisfied & 4 & 4.9 \\
Somewhat dissatisfied & 2 & 2.4 \\
\hline
\end{tabular}

Eighty-two participants, (73.9\%) reported that they currently used AT. Participants who used their AT every day were categorized as frequent AT users $(n=54)$, those who used their AT less frequently were categorized as non-frequent users $(n=28)$ (see Table 3).

Twenty-nine participants $(26.1 \%)$ reported that they were not currently using AT. For subsequent analyses we distinguish between two groups: (1) those who perceive their AT needs to be fully met $(n=64)$; and (2) those who report unmet AT needs $(n=44)$ (this includes participants who are currently using some
AT but report additional needs $(n=17)$, as well as those who are not using AT but require it $(n=27)$. Fully met AT needs referred to those who reported that they had 'no requirement' when asked to indicate if there was any AT that they required but did not currently have.

\section{AT needs and educational engagement outcomes}

As Table 4 shows, students who indicated their AT needs were fully met scored significantly higher than students with unmet AT needs on the CLEl academic self-efficacy, stress and time press (i.e., ability to cope and deal with demands) and class communication subscales; and the SCEQ performance engagement subscale. No significant differences between groups were found for the SCEQ total score and remaining CLEI and SCEQ subscales, all $p^{\prime} s>.05$.

\section{AT needs and psychosocial outcomes}

Those who reported their AT needs were met $(M=61.41$, $\mathrm{SD}=17.72$ ) scored significantly higher on academic self-efficacy for completing educational tasks, as measured by the SELF-A, than those who reported unmet AT needs $(M=53.74, S D=16.96)$ $(\mathrm{t}(101)=2.20, p<.05)$. Well-being scores (WEMWBS), were significantly higher for those whose AT needs were met $(M d n=49)$ compared to those with unmet AT needs $(M d n=44.50)(U=956$, $Z=-2.07, p<.05)$.

\section{Psychosocial impact for current at users}

AT had a positive psychosocial impact for students with disabilities in all three domains; competence, adaptability and self-esteem, as measured by the PIADS. Students who used AT 
Table 4. Group difference analyses for AT needs and educational engagement measures.

\begin{tabular}{|c|c|c|c|c|}
\hline & Met AT needs & Unmet AT needs & $\begin{array}{c}\text { Test statistic } \\
t \text { or } U\end{array}$ & $\begin{array}{l}p \text { Value } \\
\text { 2-tailed }\end{array}$ \\
\hline \multicolumn{5}{|l|}{ College Learning Effectiveness Inventory } \\
\hline Academic self-efficacy & $M d n=4.57$ & $M d n=4.18$ & $955(U)$ & $.005^{* *}$ \\
\hline Organization and attention to study & $\begin{array}{c}M=3.34 \\
S D=0.84\end{array}$ & $\begin{array}{c}M=3.12 \\
S D=0.81\end{array}$ & $1.33(\mathrm{t})$ & .188 \\
\hline Stress and time stress & $\begin{array}{c}M=3.05 \\
S D=0.78\end{array}$ & $\begin{array}{c}M=2.59 \\
S D=0.89\end{array}$ & $2.83(\mathrm{t})$ & $.006^{* *}$ \\
\hline Involvement with college activity & $\begin{array}{c}M=3.04 \\
S D=0.85\end{array}$ & $\begin{array}{c}M=2.90 \\
S D=0.69\end{array}$ & $0.87(\mathrm{t})$ & .388 \\
\hline Emotional satisfaction & $M d n=3.86$ & $M d n=3.86$ & $1298(U)$ & .490 \\
\hline $\begin{array}{l}\text { Class communication } \\
\text { Student Course Engagement Questior }\end{array}$ & $\begin{array}{c}M=3.38 \\
S D=0.81\end{array}$ & $\begin{array}{c}M=3.01 \\
S D=0.75\end{array}$ & $2.39(\mathrm{t})$ & $.019^{*}$ \\
\hline Total scale score & $M d n=90$ & $M d n=83$ & $1084.50(U)$ & .082 \\
\hline Emotional engagement & $\begin{array}{l}M=19.29 \\
S D=4.15\end{array}$ & $\begin{array}{l}M=18.16 \\
S D=4.29\end{array}$ & $1.35(\mathrm{t})$ & .180 \\
\hline Participation/interaction engagement & $\begin{array}{l}M=20.32 \\
S D=5.26\end{array}$ & $\begin{array}{l}M=20.26 \\
S D=4.28\end{array}$ & $0.06(\mathrm{t})$ & .949 \\
\hline Performance engagement & $M d n=12$ & $M d n=11$ & $1013.50(U)$ & $.027^{*}$ \\
\hline Skills engagement & $M d n=36$ & $M d n=34$ & $1116.50(\mathrm{U})$ & .125 \\
\hline
\end{tabular}

Table 5. Summary of HMR models predicting the SCEQ and CLEl subscale scores.

\begin{tabular}{|c|c|c|c|c|c|c|c|c|c|c|c|c|c|c|}
\hline \multirow[b]{2}{*}{ Variable } & \multirow[b]{2}{*}{ B } & \multicolumn{2}{|c|}{ Performance engagemen } & \multirow[b]{2}{*}{$R^{2}$} & \multirow[b]{2}{*}{ Variable } & \multirow[b]{2}{*}{ B } & \multicolumn{2}{|c|}{ Stress and time press } & \multirow[b]{2}{*}{$R^{2}$} & \multirow[b]{2}{*}{ Variable } & \multirow[b]{2}{*}{ B } & \multicolumn{2}{|c|}{ Class communication } & \multirow[b]{2}{*}{$R^{2}$} \\
\hline & & SE & $\beta$ & & & & SE & $\beta$ & & & & SE & $\beta$ & \\
\hline Step 1 & & & & 0.00 & Step 1 & & & & $0.05^{*}$ & Step 1 & & & & 0.03 \\
\hline Step 2 & & & & $0.33 * *$ & Step 2 & & & & $0.44 * *$ & Step 2 & & & & $0.35^{* *}$ \\
\hline Step 3 & & & & $0.33 * *$ & Step 3 & & & & $0.46^{* *}$ & Step 3 & & & & $0.36^{* *}$ \\
\hline (Constant) & $5.21 * *$ & 1.02 & & & (Constant) & $1.10 * *$ & 0.29 & & & (Constant) & $1.70^{* *}$ & 0.29 & & \\
\hline Gender & 0.16 & 0.49 & 0.03 & & Gender & $-0.36^{*}$ & 0.14 & -0.20 & & Gender & -0.26 & 0.14 & -0.15 & \\
\hline Well-being & 0.05 & 0.02 & 0.21 & & Well-being & $0.01^{*}$ & 0.01 & 0.19 & & Well-being & 0.01 & 0.01 & 0.18 & \\
\hline ASE & $0.06^{* *}$ & 0.02 & 0.41 & & ASE & $0.02 * *$ & 0.00 & 0.46 & & ASE & $0.02 * *$ & 0.01 & 0.41 & \\
\hline AT needs & 0.36 & 0.46 & 0.07 & $\begin{array}{c}R^{2} \text { change: } \\
0.004\end{array}$ & : AT needs & 0.22 & 0.13 & 0.13 & $\begin{array}{c}R^{2} \text { change: } \\
0.016\end{array}$ & : AT needs & 0.17 & 0.13 & 0.10 & $\begin{array}{c}R^{2} \text { change: } \\
0.010\end{array}$ \\
\hline
\end{tabular}

Abbreviation: ASE: academic self-efficacy.

${ }^{*} p<.05 ; * * p<.01$.

experienced greatest positive impact in the area of competence $(M=1.74, \mathrm{SD}=0.95$, range $=5.50[-2.50$ to 3.00$])$, followed by adaptability $(M=1.30, \mathrm{SD}=1.22$, range $=6[-3$ to 3$]$ and selfesteem $(M=1.12, \mathrm{SD}=1.00$, range $=4.50$ [ -1.50 to 3.00$]$.

Kruskal-Wallis test results revealed no significant differences on the competence, adaptability, or self-esteem subscale between any of the categories of disabilities. There was no significant correlation between age and the competence $(r=0.002)$, adaptability $(r=0.111)$, or self-esteem subscale $(r=0.194)$. In relation to gender, no significant differences were found between males and females on competence, adaptability or self-esteem subscale scores. For frequency of AT use, scores were significantly higher for frequent AT users $(M d n=2.17)$ compared to non-frequent AT users $(M d n=1.38)$ on the competence subscale $U=451.50$, $Z=-2.89, p<.01$. There were no significant differences in adaptability or self-esteem between frequent and non-frequent users.

\section{Regression analyses}

HMRs were carried out to examine the unique contribution of AT needs (met/unmet) in predicting the performance engagement subscale score of the SCEQ and the stress and time press and class communication subscales of the CLEl, when controlling for the effects of gender, well-being and academic self-efficacy (see Table 5).

Gender was entered into the model at step 1, explaining $0 \%$ of the variance in performance engagement scores $[F(1$, $100)=.001, p>.05]$. Well-being and academic self-efficacy were entered at step 2 and accounted for $32.8 \%$ of the variance in performance engagement scores $[F(3,98)=15.98, p<.05]$. The second set of predictors accounted for an additional $32.8 \%$ of variance and significantly contributed to the model [ $R$-squared change $=0.328, F$ change $(2,98)=23.97, p<.05]$. Finally, AT needs was entered as a predictor at step 3 . At this step, the model accounted for $33.3 \%$ of the variance in performance engagement scores $[F(4,97)=12.09, p<.05]$. AT needs accounted for an additional $0.4 \%$ of variance but did not significantly contribute to the model $[R$-squared change $=0.004, F$ change $(1,97)=0.60, p>.05]$. In the final model, academic self-efficacy was the only predictor that significantly contributed to the model $(B=0.06, p<.001)$.

For the stress and time press subscale, gender was entered at step 1 , explaining $5 \%$ of the variance $[F(1,100)=5.31, p<.05]$. Well-being and academic self-efficacy were entered at step 2 . At this step, the model accounted for $44 \%$ of the variance in stress and time press scores $[F(3,98)=25.71, p<.05]$. The second set of predictors accounted for an additional $39 \%$ of variance and significantly contributed to the model [ $R$-squared change $=0.39$, 
$F$ change $(2,98)=34.15, p<.05]$. AT needs was entered as a predictor at step 3 , with the model accounting for $45.6 \%$ of the variance in stress and time press scores at this step $[F(4,97)=20.34$, $p<.05]$. AT needs accounted for an additional $1.6 \%$ of variance but did not significantly contribute to the model [ $R$-squared change $=0.016, F$ change $(1,97)=2.80, p>.05$. In the final model, three of the predictors significantly contributed to the model; academic self-efficacy $(B=0.02, p<.001)$; well-being $(B=.01, p<.05)$; and gender $(B=-0.36, p<.05)$. Being female was predictive of lower scores on ability to deal with pressure and demands in comparison to males.

For the class communication subscale, gender was entered at step 1 , explaining $3.1 \%$ of the variance in scores $[F(1,100)=3.21$, $p>$.05]. The predictors well-being and academic self-efficacy were entered at step 2. At this step, the model accounted for $34.7 \%$ of the variance in class communication scores $[F(3,98)=17.39$, $p<.05]$. The second set of predictors accounted for an additional $31.6 \%$ of variance and significantly contributed to the model [ $R$ squared change $=0.316, \mathrm{~F}$ change $(2,98)=23.75, p<.05]$. AT needs was entered at step 3, with the model accounting for $35.7 \%$ of the variance in class communication scores at this step $[F(4,97)=13.49, p<.05]$. AT needs accounted for an additional $1 \%$ of variance but did not significantly contribute to the model [R-squared change $=0.01, F$ change $(1,97)=1.51, p>.05]$. In the final model, academic self-efficacy was the only predictor which significantly contributed to the model $(B=0.02, p<.001)$.

\section{Discussion}

This study is the first to examine the relationship between AT needs and multiple facets of educational engagement, and the relationship between AT needs and psychosocial outcomes broadly across a diverse sample of students with various disabilities using a wide variety of AT in higher education.

Some key findings from this study were the benefits of AT for educational engagement beyond performance of academic tasks, something which is largely ignored in previous research. Results found that those whose AT needs were fully met scored significantly higher on certain aspects of educational engagement such as academic self-efficacy, stress and time press and class communication on the CLEl compared to those with unmet AT needs. This highlights the importance of AT in these areas among a diverse sample of students with various disabilities, demonstrating that AT can be beneficial and should be considered for a wide variety of SWD in higher education. This furthers previous research which exclusively focussed on the benefits of AT for class participation [44-46] and increasing efficiency when completing tasks [47] among students within a specific disability category such as those with visual impairments or those with learning disabilities. On the SCEQ, those whose AT needs were fully met scored significantly higher on performance engagement compared to those with unmet AT needs, which is in line with previous research that AT use significantly improves grades [23,48-50]. Surprisingly, no significant difference was found between those with met and unmet AT needs on the skills engagement subscale of the SCEQ, which contradicts previous research $[23,24,51]$. However, within this study a wide variety of AT was included, some of which may not be particularly relevant for the performance of academic tasks. For example, among those with unmet needs, a smaller number indicated a need/requirement for educational assistive technology $(n=19)$ versus other types of assistive devices $(n=25)$. So, for the majority of students with unmet needs in this study, their performance of academic tasks may not have been affected by not having access to the appropriate AT. It was also surprising that there was no significant difference between those with met and unmet AT needs on the participation/interaction engagement subscale of the SCEQ, given that significant differences were found on the class communication subscale of the CLEl. While these subscales are similar, the class communication subscale is more focussed on expression of ideas or opinions while the participation/interaction subscale puts more emphasis on providing/receiving help in relation to coursework. Thus, it seems from the results that AT may be more salient for expressing opinions or participating in class discussions.

Another key finding was that AT needs was not predictive of educational engagement in any of the HMR models. This again may be because a wide variety of AT was included in this study, some of which may not be particularly relevant for students' educational engagement. AT needs was also entered as a predictor at block 3 of the models to examine unique variance explained on the outcomes. Thus, a significant amount of the variance may already have been accounted for by gender, well-being and academic self-efficacy variables. Gender accounted for little variance in each model and was only a significant predictor of stress and time press. Evidence for the role of gender in educational engagement is mixed. Some studies report it to be a significant predictor with females more engaged than males [52-54], others report no relationship or inconsistencies in its influence [55-58].

Results from this study demonstrate the importance of AT for psychosocial outcomes. Those whose AT needs were fully met scored significantly higher on self-efficacy for completing academic tasks (SELF-A), and well-being (WEMWBS), compared to those with unmet AT needs. In looking at this in a diverse sample of students with various disabilities, this furthers previous research which found AT use to be related to hope and positivity among higher education students with a specific category of disability such as learning disabilities [59] and acquired brain injuries [60]. This study was the first to explore the relationship between AT needs and academic self-efficacy for completing educational tasks among higher education SWD. This positive relationship is a key finding for those who provide support for SWD in higher education.

Another key finding of this study is the positive psychosocial impact of AT use in the areas of competence, adaptability and self-esteem for current AT users. Socio-demographic variables such as age, gender and category of disability did not have a significant influence on PIADS scores. This is perhaps because students were asked to consider the assistive technologies which impact on their educational engagement when completing the PIADS, thus students could have reflected on a wide range of different assistive technologies. In previous research where sociodemographic variables were found to influence PIADS scores, individuals reflected on a specific type or category of AT device [30-32]. In contrast, frequency of AT use was found to have a significant influence on PIADS scores. Frequent AT users scored significantly higher on the competence subscale of the PIADS compared to non-frequent AT users, supporting previous research [33], but no differences were found on the adaptability or selfesteem subscales. It should be noted however, that frequency of AT use does not always equate with importance. Some students may use their AT less frequently but for specific important tasks. These findings are highly relevant for anyone who provides services to SWD in higher education, as some SWD report lower quality of life than non-disabled peers [11]. When AT needs are met significant positive impacts beyond educational outcomes in areas such as academic self-efficacy and well-being can accrue. 
However, more quantitative studies are needed in this area to add weight to the evidence base on the benefits of AT for higher education SWD from a psychosocial perspective. For example, studies which implement a longitudinal design could examine the well-being, quality of life and academic self-efficacy of students before and after integrating AT. This would help determine whether a causal relationship exists between AT and psychosocial outcomes which could have significant implications for funding allocations to AT in educational environments.

There are some limitations to this study including complexity in measuring AT outcomes. The context-specific nature of some assistive technologies can be problematic. Students may find a particular device useful for completing one particular task (e.g., reading) but not for others (e.g., writing) [61]. Equally, some students may just require use of their AT for their educational engagement occasionally or at specific times (e.g., leading up to exams) while others may require it on a day-to-day basis. As a result, the full extent of the impacts of AT may not have been captured within a cross-sectional study design. In addition, the CLEI, SCEQ, SELF-A and WEMWBS are not AT specific outcome measures. This means that they may not be sensitive enough to detect changes which are specific to AT use and may fail to differentiate the subtleties of AT use or non-use among those with disabilities. This was one of the fundamental reasons for including the PIADS, an AT-specific psychosocial measure, over other generic psychosocial measures [43]. In addition, while asking participants to self-report additional requirements for AT may be considered a strength, it could also be considered a weakness. Some participants may perceive their AT needs to be fully met and indicate they have no additional requirement for AT but this may be due to a lack of awareness of certain technologies and their potential benefits.

Another limitation of this study was the representativeness of the sample. It is possible that highly engaged students may be more likely to come forward and participate in research compared to students who are less engaged, making it hard to detect differences in educational engagement. In addition, only seven participants who were not registered with the disability support services within their institutions took part despite employing a comprehensive recruitment strategy. Individuals who refrain from registering may not identify as disabled or fear stigmatization as a result of disclosing their disability and thus, are prevented from accessing specialized supports or accommodations within the HEI $[62,63]$. Alternatively, individuals may simply prefer using assistive features on mainstream devices to meet their needs [64] and may have no requirement for registration with disability services. It is possible that the effects of AT use may be different for these students versus those who openly disclose their disability and AT use. Future research should explore perspectives and experiences regarding AT among students who have decided not to register with disability services.

There are other promising avenues for further research arising from this study. There is a clear need to develop validated AT specific outcome measures for educational engagement. These measures would ask individuals to consider the impact of their AT when completing items and thus be more sensitive to the effects of AT use, like other AT specific measures such as the PIADS [42]. This would enable consistency in the measurement of the impacts of AT for SWD and enable comparison across countries and cultures, something which is lacking from the literature at present [65]. This is a fundamental step in moving towards the development of evidence based AT practices in higher education. Future research should also explore students' perceptions of what AT characteristics are most important in contributing to their psychological and social well-being.

In conclusion, this study has important implications for both SWD in higher education and those who provide supports to these students such as Disability/AT Officers. Findings from this study highlight that AT is beneficial across a diverse sample of students with various disabilities in terms of their educational engagement in certain domains and psychosocial outcomes including academic self-efficacy, well-being, competence, adaptability and self-esteem. This demonstrates the wide-reaching benefits of AT beyond simply enabling students to engage more easily in academic tasks such as reading and writing. These findings may be useful in terms of informing funding allocations to HEls for AT by highlighting the positive implications of providing SWD with the appropriate AT supports. In addition, Disability/AT Offices within HEls need to be cognizant of the benefits of AT not only from an educational perspective, but also psychological and social perspectives, and prioritize meeting the AT needs of SWD. Incorporating AT with an institution wide approach to universal design for learning is key for promoting a sense of inclusion for SWD while also reducing the need for accommodations [66]. It is essential for HEls to consider supporting SWD as a responsibility which extends beyond the disability support office, to create a truly inclusive environment for these students and progress towards the adoption of a social model of disability approach [67].

\section{Disclosure statement}

No potential conflict of interest was reported by the author(s).

\section{Funding}

This work was supported by the Irish Research Council Government of Ireland Postgraduate Scholarship (Project ID GOIPG/2019/2471).

\section{ORCID}

Aoife McNicholl (D) http://orcid.org/0000-0002-1799-1483

Deirdre Desmond (iD http://orcid.org/0000-0002-6746-7006

Pamela Gallagher (iD http://orcid.org/0000-0001-5558-1269

\section{References}

[1] Association for Higher Education Access and Disability (AHEAD). Numbers of students with disabilities studying in higher education in Ireland 2017/18. Dublin: AHEAD Educational Press; 2019.

[2] Human Resources and Skills Development Canada. Federal disability reference guide; 2013. Available from: https:// www.canada.ca/content/dam/esdc-edsc/migration/documents/eng/disability/arc/reference_guide.pdf.

[3] Koshy P. Equity student participation in Australian higher education: 2012-2017. Perth: National Centre for Student Equity in Higher Education, Curtin University; 2018.

[4] National Center for Education Statistics. Digest of education statistics 2016. Washington (DC): U.S. Department of Education; 2018.

[5] Riddell S. The inclusion of disabled students in higher education in Europe: progress and challenges. Paper presented 
at the Italian university conference of delegates for disabilities; 2016 May 12-14; University of Turin, Turin.

[6] Vaccaro A, Daly-Cano M, Newman BM. A sense of belonging among college students with disabilities: an emergent theoretical model. J Coll Stud Dev. 2015;56(7):670-686.

[7] Foreman P, Dempsey I, Robinson G, et al. Characteristics, academic and post-university outcomes of students with a disability at the university of Newcastle. High Educ Res Dev. 2001;20(3):313-325.

[8] Mullins L, Preyde M. The lived experience of students with an invisible disability at a Canadian university. Disabil Soc. 2013;28(2):147-160.

[9] Sachs D, Schreuer N. Inclusion of students with disabilities in higher education: performance and participation in student's experiences. Disabil Stud Q. 2011;31(2).

[10] Hall CW, Webster RE. Metacognitive and affective factors of college students with and without learning disabilities. J Postsecond Educ Disabil. 2008;21(1):32-41.

[11] Herts KL, Wallis E, Maslow G. College freshmen with chronic illness: a comparison with healthy first-year students. J Coll Stud Dev. 2014;55(5):475-480.

[12] Mullins AJ, Gamwell KL, Sharkey CM, et al. Illness uncertainty and illness intrusiveness as predictors of depressive and anxious symptomology in college students with chronic illnesses. J Am Coll Health. 2017;65(5):352-360.

[13] Arnett JJ. Emerging adulthood: a theory of development from the late teens through the twenties. Am Psychol. 2000;55(5):469-480.

[14] Bell D, Carl A, Swart E. Students with hearing impairment at a South African university: self-identity and disclosure. Afr J Disabil. 2016;5(1):a229.

[15] Goode J. Managing' disability: early experiences of university students with disabilities. Disabil Soc. 2007;22(1):35-48.

[16] Moriña A. We aren't heroes, we're survivors': higher education as an opportunity for students with disabilities to reinvent an identity. J Furth Higher Educ. 2017;41(2): 215-226.

[17] Ule M. Identity challenges and social experiences of higher education students with disabilities in Slovenia. Disabil Soc. 2017;32(10):1592-1607.

[18] MacLachlan M, Banes D, Bell D, et al. Assistive technology policy: a position paper from the first global research, innovation, and education on assistive technology (GREAT) summit. Disabil Rehabil Assist Technol. 2018;13(5):454-466.

[19] Thordardottir B, Malmgren Fänge A, Lethin C, et al. Acceptance and use of innovative assistive technologies among people with cognitive impairment and their caregivers: a systematic review. Biomed Res Int. 2019;2019: 9196729.

[20] Wessels R, Dijcks B, Soede $M$, et al. Non-use of provided assistive technology devices, a literature overview. TAD. 2004;15(4):231-238.

[21] Assistive Technology [internet]. Geneva: World Health Organisation; 2018 May 18 [cited 2020 Jul 1]. Available from: https://www.who.int/en/news-room/fact-sheets/ detail/assistive-technology.

[22] McNicholl A, Casey H, Desmond D, et al. The impact of assistive technology use for students with disabilities in higher education: a systematic review. Disabil Rehabil: Assist Technol. 2019;1-14. DOI:10.1080/17483107.2019. 1642395

[23] Malcolm MP, Roll MC. The impact of assistive technology services in post-secondary education for students with disabilities: intervention outcomes, use-profiles, and userexperiences. Assist Technol. 2017;29(2):91-98.

[24] Schmitt AJ, McCallum E, Hennessey J, et al. Use of reading pen assistive technology to accommodate post-secondary students with reading disabilities. Assist Technol. 2012; 24(4):229-239.

[25] Chiang HY, Jacobs K. Effect of computer-based instruction on students' self-perception and functional task performance. Disabil Rehabil Assist Technol. 2009;4(2):106-118.

[26] Getzel EE, Thoma CA. Experiences of college students with disabilities and the importance of self-determination in higher education settings. Career Dev Except Individ. 2008; 31(2):77-84.

[27] Wessel RD, Jones $\mathrm{D}$, Blanch $\mathrm{CL}$, et al. Pre-enrollment considerations of undergraduate wheelchair users and their post-enrollment transitions. J Postsecond Educ Disabil. 2015;28(1):57-72.

[28] Craddock G. The AT continuum in education: novice to power user. Disabil Rehabil Assist Technol. 2006;1(1-2): 17-27.

[29] Marschark M, Machmer E, Spencer LJ, et al. Language and psychosocial functioning among deaf learners with and without cochlear implants. J Deaf Stud Deaf Educ. 2018; 23(1):28-40.

[30] Jiménez Arberas $E$, Ordoñez Fernández F, Rodríguez Menéndez S. Psychosocial impact of mobility assistive technology on people with neurological conditions. Disabil Rehabil Assist Technol. 2019;1-7. DOI:10.1080/17483107. 2019.1648571

[31] Nordström B, Nyberg L, Ekenberg L, et al. The psychosocial impact on standing devices. Disabil Rehabil Assist Technol. 2014;9(4):299-306.

[32] Pousada Garcia T, Groba González B, Nieto Rivero L, et al. Exploring the psychosocial impact of wheelchair and contextual factors on quality of life of people with neuromuscular disorders. Assist Technol. 2015;27(4):246-256.

[33] Saunders GH, Jutai JW. Hearing specific and generic measures of the psychosocial impact of hearing aids. J Am Acad Audiol. 2004;15(3):238-248.

[34] Leonardi M, Bickenbach J, Ustun TB, et al. The definition of disability: what is in a name? Lancet. 2006;368(9543): 1219-1221.

[35] Khasnabis C, Mirza Z, MacLachlan M. Opening the GATE to inclusion for people with disabilities. Lancet. 2015; 386(10010):2229-2230.

[36] Newton FB, Kim E, Wilcox D, et al. College learning effectiveness inventory: administration and scoring manual for CLEl. Manhattan (KS): K-CAT; 2008.

[37] Krumrei-Mancuso EJ, Newton FB, Kim E, et al. Psychosocial factors predicting first-year college student success. J Coll Stud Dev. 2013;54(3):247-266.

[38] Handelsman MM, Briggs WL, Sullivan N, et al. A measure of college student course engagement. J Educ Res. 2005;98(3): 184-192.

[39] Brown SJ, White S, Bowmar A, et al. Student engagement in a compulsory introductory physiology course. JoSoTL. 2017;17(1):52-62.

[40] Zimmerman B, Kitsantas A. Reliability and validity of selfefficacy for learning form (SELF) scores of college students. J Psychol. 2007;215(3):157-163.

[41] Tennant R, Hiller L, Fishwick R, et al. The warwick-edinburgh mental well-being scale (WEMWBS): development 
and UK validation. Health Qual Life Outcomes. 2007;5(1): 63-75.

[42] Day $H$, Jutai J. The psychosocial impact of assistive devices scale: PIADS manual. Toronto: Authors; 1996.

[43] Day H, Jutai J, Campbell K. Development of a scale to measure the psychosocial impact of assistive devices: lessons learned and the road ahead. Disabil Rehabil. 2002; 24(1-3):31-37.

[44] Foley AR, Masingila JO. The use of mobile devices as assistive technology in resource-limited environments: access for learners with visual impairments in Kenya. Disabil Rehabil Assist Technol. 2015;10(4):332-339.

[45] Kuzu A. The factors that motivate and hinder the students with hearing impairment to use mobile technology. Turk Online J Educ Technol. 2011;10(4):336-348.

[46] Lartz MN, Stoner JB, Stout LJ. Perspectives of assistive technology from deaf students at a hearing university. Assist Technol Outcomes Benefits. 2008;5(1):72-91.

[47] Floyd KK, Judge SL. The efficacy of assistive technology on reading comprehension for postsecondary students with learning disabilities. Assist Technol Outcomes Benefits. 2012;8(1):48-64.

[48] Bhardwaj RK, Kumar S. A comprehensive digital environment for visually impaired students: user's perspectives. Libr Hi Tech. 2017;35(4):549-564.

[49] Christ T. Technology support services in postsecondary education: a mixed methods study. TAD. 2008;20(1):25-35.

[50] Nelson LM, Reynolds TW. Speech recognition, disability, and college composition. J Postsecond Educ Disabil. 2015; 28(2):181-197.

[51] Malcolm MP, Roll MC. Self-reported assistive technology outcomes and personal characteristics in college students with less-apparent disabilities. Assist Technol. 2019;31(4): 169-179.

[52] Kinzie J, Gonyea R, Kuh GD, et al. The relationship between gender and student engagement in college. Paper presented at the association for the study of higher education annual conference; 2007 November 8-10; Louisville, KY.

[53] Mooney O, Patterson V, O'Connor M, et al. A study of progression in Irish higher education. Dublin: Higher Education Authority; 2010.

[54] Oga-Baldwin QW, Nakata Y. Engagement, gender, and motivation: a predictive model for Japanese young language learners. System. 2017;65:151-163.

[55] Cole JS, Korkmaz A. First-year students' psychological wellbeing and need for cognition: are they important predictors of academic engagement? J Coll Stud Dev. 2013; 54(6):557-569.

[56] Maguire R, Egan A, Hyland $P$, et al. Engaging students emotionally: the role of emotional intelligence in predicting cognitive and affective engagement in higher education. High Educ Res Dev. 2017;36(2):343-357.

[57] Soria KM, Stebleton MJ. First-generation students' academic engagement and retention. Teach High Educ. 2012;17(6): 673-685.

[58] Zhao CM, Carini R, Kuh GD. Searching for the peach blossom Shangri-La: student engagement of men and women SMET majors. Rev High Educ. 2005;28(4):503-525.

[59] Heiman T, Shemesh DO. Students with LD in higher education: use and contribution of assistive technology and website courses and their correlation to students' hope and well-being. J Learn Disabil. 2012;45(4):308-318.

[60] Hendricks DJ, Sampson E, Rumrill P, et al. Activities and interim outcomes of a multi-site development project to promote cognitive support technology use and employment success among postsecondary students with traumatic brain injuries. NeuroRehabilitation. 2015;37(3): 449-458.

[61] Smith RO. Measuring assistive technology outcomes in education. Diagnostique. 2000;25(4):273-290.

[62] Kendall L. Higher education and disability: exploring student experiences. Cogent Educ. 2016;3(1):1-12.

[63] Thompson-Ebanks V, Jarman M. Undergraduate students with nonapparent disabilities identify factors that contribute to disclosure decisions. Int J Disabil Dev Educ. 2018; 65(3):286-303.

[64] Shinohara K, Wobbrock JO. Self-conscious or self-confident? A diary study conceptualizing the social accessibility of assistive technology. ACM Trans Access Comput. 2016;8(2): $1-31$.

[65] Edyburn DL, Smith RO. Creating an assistive technology outcomes measurement system: validating the components. Assist Technol Outcomes Benefits. 2004;1(1):8-15.

[66] Kraglund-Gauthier WL, Young DC, Kell E. Teaching students with disabilities in post-secondary landscapes: navigating elements of inclusion, differentiation, universal design for learning, and technology. Transform Dialogues: Teach Learn J. 2014;7(3):1-9.

[67] Mole H. A US model for inclusion of disabled students in higher education settings: the social model of disability and universal design. Wide Particip Lifelong Learn. 2013; 14(3):62-86. 